\title{
Stress Tolerance and Environmental Fitness of Pseudomonas fluorescens A506, Which Has a Mutation in rpoS
}

\author{
Mary J. Hagen, Virginia O. Stockwell, Cheryl A. Whistler, Kenneth B. Johnson, and Joyce E. Loper
}

First, second, fourth, and fifth authors: Department of Botany and Plant Pathology, and third author: Cellular and Molecular Biology Program, Oregon State University, Corvallis 97331; and fifth author: U.S. Department of Agriculture-Agricultural Research Service, Horticultural Crops Research Laboratory, 3420 NW Orchard Avenue, Corvallis, OR 97330.

Current address of M. J. Hagen: Veterinary \& Animal Sciences, University of Massachusetts, Amherst.

Current address of C. A. Whistler: Department of Microbiology, University of New Hampshire, Durham.

Accepted for publication 20 January 2009.

\section{ABSTRACT}

Hagen, M. J., Stockwell, V. O., Whistler, C. A., Johnson, K. B., and Loper, J. E. 2009. Stress tolerance and environmental fitness of Pseudomonas fluorescens A506, which has a mutation in rpoS. Phytopathology 99:679-688.

Establishment of suppressive populations of bacterial biological control agents on aerial plant surfaces is a critical phase in biologically based management of floral diseases. Periodically, biocontrol agents encounter inhospitable conditions for growth on plants; consequently, tolerance of environmental stresses may contribute to their fitness. In many gramnegative bacteria, including strains of Pseudomonas spp., the capacity to survive environmental stresses is influenced by the stationary phase sigma factor RpoS. This study focused on the role of RpoS in stress response and epiphytic fitness of Pseudomonas fluorescens A506, a well- studied bacterial biological control agent. We detected a frameshift mutation in the rpoS of A506 and demonstrated that the mutation resulted in a truncated, nonfunctional RpoS. Using site-directed mutagenesis, we deleted a nucleotide from rpoS, which then encoded a full-length, functional RpoS. We compared the stress response and epiphytic fitness of A506 with derivative strains having the functional full-length RpoS or a disrupted, nonfunctional RpoS. RpoS had little effect on stress response of A506 and no consistent influence on epiphytic population size of A506 on pear or apple leaves or flowers. Although the capacity of strain A506 to withstand exposure to environmental stresses was similar to that of other fluorescent pseudomonads, this capacity was largely independent of rpos.

Additional keywords: BlightBan, fire blight, fruit surfaces, phyllosphere.
More than 40 biological control agents are now available commercially for management of plant diseases in agriculture (14). One of these products is BlightBan A506, composed of the biological control agent Pseudomonas fluorescens strain A506 (56), which is used primarily for the suppression of the bacterial disease fire blight on pear and apple. If applied to flowers at early to mid-bloom, A506 can proliferate on pear and apple stigmas and exclude the pathogen from infection sites $(29,69)$. The incidence of fire blight on flowers is reduced by $\approx 60 \%$ with two applications of A506 in orchards in California $(28,29)$ and by $\approx 30 \%$ in pathogen-inoculated experimental plots in the Pacific Northwest (V. O. Stockwell, K. B. Johnson, and J. E. Loper, unpublished data). In all, 7,000 to 10,000 lbs. of BlightBan A506 were applied annually to pear and apple orchards in the United States in the late 1990s, and up to $30 \%$ of the orchard acreage in California alone was treated with two applications of the product (U.S. Department of Agriculture-National Agricultural Statistics Service). BlightBan A506 is also registered for application to cherry, almond, peach, tomato, potato, strawberry, and pome fruit for suppression of frost injury and to pear for management of fruit russeting associated with IAA-producing epiphytic bacteria (56). BlightBan A506 can control several production constraints, is relatively easy to apply, and can be integrated with antibiotics for

Corresponding author: V. O. Stockwell

E-mail address: stockwev@science.oregonstate.edu

\section{doi:10.1094/PHYTO-99-6-0679}

This article is in the public domain and not copyrightable. It may be freely reprinted with customary crediting of the source. The American Phytopathological Society, 2009. plant disease control $(28,53)$. These characteristics undoubtedly contribute to the adoption of this biological control product by growers.

P. fluorescens A506 is most effective for biological control of fire blight if it is established on stigmatic surfaces before colonization and infection of flowers by Erwinia amylovora (69). Because consistent and early colonization of stigmas by the antagonist is required to suppress fire blight, we expect that improvements in the initial establishment of A506 on flowers will enhance biological control of this disease. Aerial surfaces of plants, such as flowers, can be inhospitable to bacterial growth because bacterial cells are exposed to UV irradiation, rapid changes in temperature and water availability, and coincident fluctuations in osmotic potential and nutrient availability (27). Populations of Pseudomonas spp. applied to aerial surfaces of plants under hot and dry conditions may decrease rapidly $(3,4,68)$. The capacity to survive desiccation and osmotic stress are epiphytic fitness traits of $P$. syringae (26) and are also likely to influence the capacity of biological control agents like A506 to survive on aerial plant surfaces.

In many gram-negative bacteria, including strains of $P$. fluorescens and other Pseudomonas spp., the capacity to survive desiccation and other environmental stresses is influenced by the stationary phase sigma factor $\sigma^{\mathrm{S}}(47,55)$. The sigma subunit is a dissociable protein of the eubacterial RNA polymerase holoenzyme responsible for promoter specificity in the initiation of transcription (17). Under conditions of cellular starvation, $\sigma^{\mathrm{S}}$ accumulates, binds, and directs the RNA polymerase holoenzyme to many genes with diverse functions, including stress response. rpoS mutants of Pseudomonas spp. commonly exhibit diminished survival in the stationary phase when subjected to environmental 
and physiological stresses, including carbon starvation, UV irradiation, desiccation, and osmotic stress (16,21,32-34,44,47,55,57). Furthermore, rpoS mutants of $P$. fluorescens Pf-5 exhibit diminished capacity to colonize the rhizosphere of plants grown in dry soil (55), establishing $r p o S$ as a fitness factor of this bacterium.

Due to the importance of stress response in the epiphytic fitness of $P$. syringae (26) and of rpoS in the stress response of many strains of Pseudomonas spp. (16,21,25,32-34,44,47,55,57), we initiated this study to determine the role of $r p o S$ in epiphytic fitness of A506. In addition to its importance as a biological control agent, A506 has been widely studied as a model organism in experiments evaluating resource competition $(9,27)$, biosensors of the chemical nature of microbial habitats $(6,51,60,70)$, and survival and growth of bacteria on aerial plant surfaces $(20,30,31$, $35,36)$. Soon after we initiated this study, we were surprised to discover that the rpoS of A506 has a frameshift mutation that results in a truncated, nonfunctional RpoS. We then explored the possibility of enhancing the stress resistance of A506 by repairing the rpoS to result in a full-length functional RpoS. A506 derivatives, which differed only in having a functional or nonfunctional RpoS, were compared for stress response in the laboratory and for epiphytic fitness on flowers and leaves of pear or apple in replicated field experiments. The results of these experiments indicate that $r p o S$ had a minor role in stress response or epiphytic fitness of A506.

\section{MATERIALS AND METHODS}

Bacterial strains and growth conditions. Bacterial strains and plasmids are listed in Table 1. Escherichia coli was cultured on Luria-Bertani (LB) medium (46) at $37^{\circ} \mathrm{C}$. Pseudomonas strains were cultured at $27^{\circ} \mathrm{C}$ on LB, King's medium B (KB) (24), Pseudomonas agar F (PAF) (Difco Laboratories, Detroit), M9 minimal medium (M9) (46), or nutrient agar (Difco Laboratories) containing 1\% (wt/vol) glycerol (NAgly). Antibiotics (SigmaAldrich, St. Louis) were used in the following concentrations: ampicillin at $100 \mu \mathrm{g} / \mathrm{ml}$, cycloheximide at $50 \mu \mathrm{g} / \mathrm{ml}$, kanamycin at $50 \mu \mathrm{g} / \mathrm{ml}$, rifampicin at $100 \mu \mathrm{g} / \mathrm{ml}$, and tetracycline at $20 \mu \mathrm{g} / \mathrm{ml}$ (E. coli) or $200 \mu \mathrm{g} / \mathrm{ml}$ (P. fluorescens).

Recombinant DNA techniques. Isolation of plasmids and genomic DNA, restriction digests, ligations, transformations, and gel electrophoresis were performed using standard methods (46). Plasmids pJEL01, pME3087, and pRK415 and their derivatives were mobilized from E. coli S17-1 into P. fluorescens A506 and Pf-5 using biparental matings.

Cloning of the rpoS gene from $P$. fluorescens strain A506. Southern analysis of EcoRI-digested genomic DNA from A506 demonstrated that a single restriction fragment of $\approx 3.0 \mathrm{~kb}$ hybridized to the rpoS gene from $P$. fluorescens Pf-5 (47). A minilibrary was constructed by cloning EcoRI-digested fragments of $\approx 3.0 \mathrm{~kb}$ from genomic DNA of A506 into pUC19, and introducing these constructs into E. coli $\mathrm{DH} 5 \alpha$ by transformation. Transformants were screened by colony hybridization to identify clones that hybridized to the rpoS gene of Pf-5. The plasmid from one transformant, pJEL5964, was digested with EcoRI and the 2.9-kb insertion was cloned into pJEL01 to construct pJEL5942.

DNA sequencing and sequence analysis. DNA sequencing and oligonucleotide syntheses were performed at the Center for Gene Research and Biotechnology at Oregon State University, Corvallis and by Macromolecular Resources at Colorado State University, Fort Collins. Sequencing of the 2.5-kb EcoRI-XhoI fragment containing the rpoS gene from A506 cloned in pJEL5936 was initiated using the forward and reverse sequencing primers to pUC19. Subsequent sequencing was directed by primers designed from previous sequence determination of the region. The GenBank accession number for the sequence of the native $\operatorname{rpoS}$ of A506 reported in this article is FJ384964.

Site-directed mutagenesis of the $\operatorname{rpoS}$ gene. Because the native $r p o S$ of A506 was found to contain a single nucleotide insertion, which introduced a stop codon and resulted in a truncated RpoS protein (Fig. 1), the gene was termed $r p o S^{\mathrm{fs}}$ (for $r p o S$ with the frameshift mutation). To generate a repaired, full-length rpoS

TABLE 1. Strains and plasmids used in this study

\begin{tabular}{|c|c|c|}
\hline Strain or plasmid & Relevant characteristics ${ }^{\mathrm{z}}$ & Reference \\
\hline \multicolumn{3}{|c|}{ Pseudomonas fluorescens } \\
\hline A506 & Rif $^{\mathrm{r}}$ mutant of an isolate from a pear leaf; $r p o S^{\mathrm{fs}}$ & 28 \\
\hline A506 rpoS $S^{\mathrm{fs}}:: l a c Z$ & Also called JL4528 & This study \\
\hline A506 rpoS::nptI & Also called JL4529 & This study \\
\hline A506 rpos $S^{+}$ & Also called JL4543 & This study \\
\hline Pf-5 & $\begin{array}{l}\text { Field isolate from a cotton root. Produces numerous secondary metabolites including pyrrolnitrin, pyoluteorin } \\
\text { and 2,4-diacetylphloroglucinol }\end{array}$ & 47 \\
\hline Pf-5 rpoS::Tn5 & Also called JL3985 & 47 \\
\hline \multicolumn{3}{|l|}{ Escherichia coli } \\
\hline S17-1 & recA thi pro $h s d R^{-} \mathrm{M}^{+} \mathrm{RP} 4:: 2-\mathrm{Tc}:: \mathrm{Mu}:: \mathrm{Km} \operatorname{Tn} 7 \mathrm{Sm}^{\mathrm{r}}, \mathrm{Tp}^{\mathrm{r}}$ & 50 \\
\hline \multicolumn{3}{|c|}{${ }^{2}$} \\
\hline pME3087 & $M o b^{+}$, ColE1 replicon, $\mathrm{Tc}^{\mathrm{r}}$ & 65 \\
\hline pRK415 & IncP1 replicon, polylinker of pUC19, $\mathrm{Mob}^{+} \mathrm{Tc}^{\mathrm{r}}$ & 22 \\
\hline pRK252 & IncP1 replicon, $\mathrm{Mob}^{+} \mathrm{Tc}^{\mathrm{r}}$ & 10 \\
\hline pUC19 & ColE1 replicon, $\mathrm{Amp}^{\mathrm{r}}$ & 46 \\
\hline pUC4K & Source of $n p t I, \mathrm{Km}^{\mathrm{r}}$ & 64 \\
\hline pJEL01 & p15A replicon, $\mathrm{Mob}^{+} \mathrm{Cm}^{\mathrm{r}}, \mathrm{Tc}^{\mathrm{r}}$ & 47 \\
\hline pJEL5649 & 2.9-kb genomic fragment of Pf-5 encompassing $r p o S$ cloned into pJEL01, Tc ${ }^{r}$ & 47 \\
\hline pJEL5925 & 2.9-kb EcoRI fragment containing $r p o S^{\mathrm{fs}}$ of A506 cloned into pME3087, $\mathrm{Tc}^{\mathrm{r}}$ & This study \\
\hline pJEL5936 & 2.5-kb EcoRI-XhoI fragment from pJEL5925 cloned into pUC19, Amp ${ }^{\mathrm{r}}$ & This study \\
\hline pJEL5942 & 2.9-kb EcoRI fragment containing $r p o S^{\mathrm{fs}}$ of A506 cloned into pJEL01, $\mathrm{Tc}^{\mathrm{r}}$ & This study \\
\hline pJEL5964 & 2.9-kb EcoRI fragment containing $r p o S^{\mathrm{fs}}$ of A506 cloned into pUC19, Amp ${ }^{\mathrm{r}}$ & This study \\
\hline pJEL5968 & $\begin{array}{l}\text { 4.3-kb EcoRI fragment composed of 1.4-kb AccI fragment containing } n p t I \text { from pUC4K cloned into ClaI site of } \\
\text { pJEL5964 (rpoS::nptI); } \mathrm{Amp}^{\mathrm{r}}, \mathrm{Km}^{\mathrm{r}}\end{array}$ & This study \\
\hline pJEL5975 & 4.3-kb EcoRI fragment from pJEL5968 containing rpoS::nptI cloned into pME3087; $\mathrm{Km}^{\mathrm{r}}, \mathrm{Tc}^{\mathrm{r}}$ & This study \\
\hline pJEL6014 & 7.1-kb EcoRI fragment containing $r p o S^{\mathrm{fs}}:: l a c Z$ cloned into pRK252; Tc $\mathrm{c}^{\mathrm{r}}$ & This study \\
\hline pJEL6067 & 2.9-kb EcoRI fragment containing a repaired A506 rpoS ${ }^{+}$, cloned into pRK415; $\mathrm{Tc}^{\mathrm{r}}$ & This study \\
\hline pJEL6068 & 2.9-kb EcoRI fragment containing a repaired A506 rpoS ${ }^{+}$, cloned into pJEL01; $\mathrm{Tc}^{\mathrm{r}}$ & This study \\
\hline pJEL6069 & 2.9-kb EcoRI fragment containing a repaired $\mathrm{A} 506 \mathrm{rpoS}^{+}$, cloned into pUC19; $\mathrm{Amp}^{\mathrm{r}}$ & This study \\
\hline
\end{tabular}

${ }^{\mathrm{z}} \mathrm{Amp}^{\mathrm{r}}, \mathrm{Cm}^{\mathrm{r}}, \mathrm{Km}^{\mathrm{r}}, \mathrm{Rif}^{\mathrm{r}}, \mathrm{Sm}^{\mathrm{r}}, \mathrm{Tc}^{\mathrm{r}}$, and $\mathrm{Tp}^{\mathrm{r}}$ indicate resistance to ampicillin, chloramphenicol, kanamycin, rifampicin, streptomycin, tetracycline, and trimethoprim, respectively. $r p o S^{\mathrm{fs}}$ indicates the native gene from A506, which confers a truncated protein product; $r p o S^{+}$indicates a repaired gene that confers a full-length, functional protein product. 
(termed $\mathrm{rpoS}^{+}$), the guanosine residue at site 231 was excised from rpoS $S^{\mathrm{fs}}$ using polymerase chain reaction (PCR). Primers Int1a 5'CGGCTTTTCCCCTCTGTTACCCCCCGAAGAAGAAGT-3' and Int2a 5'-ACTTCTTCTTCGGGGGGTAACAGAGGGGAAAAGCCG-3' are identical to $r p o S^{\mathrm{fs}}$ of A506 at sites 212 to 248 except at position 231 , where they are missing a guanosine residue. Int la and the pUC19 reverse sequencing primer were used to amplify the $3^{\prime}$ end of $r p o S^{\mathrm{fs}}$ in pJEL5964. Int2a and the pUC19 forward sequencing primer were used to amplify the $5^{\prime}$ end of $r p o S^{\mathrm{fs}}$ from pJEL5964. Amplification products from these reactions were gel isolated and used as template in a PCR with the pUC19 forward and reverse sequencing primers. The amplification product from this reaction $\left(r p o S^{+}\right)$was digested with EcoRI and cloned into pUC19, pRK415, and pJEL01 resulting in pJEL6069, pJEL6067, and pJEL6068, respectively. The absence of guanosine at position 231 and the integrity of all other nucleotides in $\operatorname{rpoS}^{+}$were confirmed by sequencing the insert of pJEL6069.

Reconstruction of the $r p o S$ gene in A506. $r p o S^{\text {fs }}$ of A506 was replaced with rpoS $S^{+}$from pJEL6069 in a two-step process. A 4.1kb blunt-ended SmaI fragment from pMini-Tn5lacZ1 (8), which contains lacZ, was inserted into the blunted ClaI site in rpoS $S^{\mathrm{fs}}$. The 7.1-kb EcoRI fragment containing the $r p o S^{\mathrm{fs}}:: l a c Z$ fusion was cloned into pRK252 to construct pJEL6014, which was introduced into A506 via conjugation. Blue, $\mathrm{Tc}^{\mathrm{r}}$ colonies were inoculated into fresh $\mathrm{KB}$ broth, incubated with shaking at $27^{\circ} \mathrm{C}$, subcultured daily $(1 \% \mathrm{vol} / \mathrm{vol})$ into fresh broth, and dilutions were spread onto KB agar supplemented with X-gal. Blue colonies were spotted onto replica plates containing $\mathrm{KB} \mathrm{Tc}$, and $\mathrm{Tc}^{\mathrm{s}}$ colonies were considered to be putative mutants in which $r p o S^{\mathrm{fs}}:: \operatorname{lac} Z$ had replaced $r p o S^{\mathrm{fs}}$. The replacement event was confirmed by Southern analysis using the 7.1-kb insert of pJEL6014 as a probe, and one $\operatorname{rpoS}^{\mathrm{fs}}::$ lacZ derivative of A506 (JL4528) was selected for further study. The 2.9-kb EcoRI fragment containing $r p o S^{+}$from pJEL6067 was introduced into the genome of JL4528 using the same methods, and replacement of $r p o S^{\mathrm{fs}}:: \operatorname{lacZ}$ with $r p o S^{+}$in a white, $\mathrm{Tc}^{\mathrm{s}}$ colony (JL4543) was confirmed by Southern and DNA sequence analysis.

Allelic exchange mutagenesis of the $\operatorname{rpoS}^{\text {fs }}$ gene in $\mathbf{A 5 0 6}$. The $n p t I$ cartridge from pUC4K was cloned into the internal ClaI site of $r p o S^{\mathrm{fs}}$ in pJEL5964 to make pJEL5968. The rpoS::nptI insertion from pJEL5968 was cloned into the suicide vector pME3087 as an EcoRI fragment to generate pJEL5975, which was introduced into A506 via conjugation. Putative double crossover mutants of A506 (i.e., $\mathrm{Km}^{\mathrm{r}}$, Rif ${ }^{\mathrm{r}}$, and $\mathrm{Tc}^{\mathrm{s}}$ ) were confirmed as such following Southern analysis using the 2.9-kb EcoRI fragment of pJEL5964 (rpoS ${ }^{\mathrm{fs}}$ of A506) and the 4.3-kb EcoRI fragment of pJEL5968 (rpoS::nptI) as probes.

Western blot analysis. Bacterial cultures were grown at $27^{\circ} \mathrm{C}$ in LB broth and sampled during exponential phase and stationary phase. Cells were harvested, immediately frozen in liquid nitrogen, and extracted by boiling in protein sample buffer (Bio-Rad Laboratories, Hercules, CA) containing 5\% 2-mercaptoethanol. Proteins were separated on a $12 \%$ sodium dodecyl sulfate polyacrylamide gel electrophoresis gel and transferred onto a nitrocellulose membrane (Bio-Rad Laboratories). Blots were incubated with polyclonal antibodies to $E$. coli $\sigma^{\mathrm{S}}$, supplied by K. Tanaka (59), and the antibodies were detected by enhanced chemiluminescence according to the manufacturer's protocol (Amersham Life Science Inc, Arlington Heights, IL).

Complementation of rpoS in P. fluorescens Pf-5. Plasmids containing rpoS ${ }^{\mathrm{fs}}$ (pJEL5942) or rpoS $^{+}$(pJEL6068) from A506 were introduced into an rpoS mutant of Pf-5 (JL3985) to determine if the genes could complement the rpoS mutation in that strain. Tryptophan side chain oxidase activity, which requires a functional rpoS in strain Pf-5, was assessed as described by Takai and Hayaishi (58). A mutation in $r p o S$ also alters the production of the secondary metabolites pyoluteorin and pyrrolnitrin by Pf-5 $(43,47)$. Production of pyoluteorin and pyrrolnitrin was detected using reverse-phase thin-layer chromatography following the method described by Pfender and associates (43).

Growth rate determinations. Bacterial strains were grown at $27^{\circ} \mathrm{C}$ with shaking $(200 \mathrm{rpm})$ in replicate test tubes containing 5 -ml broth cultures of LB, KB, M9 with $1 \%$ glucose (wt/vol), or M9 with $1 \%$ glycerol (vol/vol). Periodically over $36 \mathrm{~h}$, the optical density of cultures was measured at $\lambda 600 \mathrm{~nm}$ with a spectrophotometer. The experiment was repeated twice.

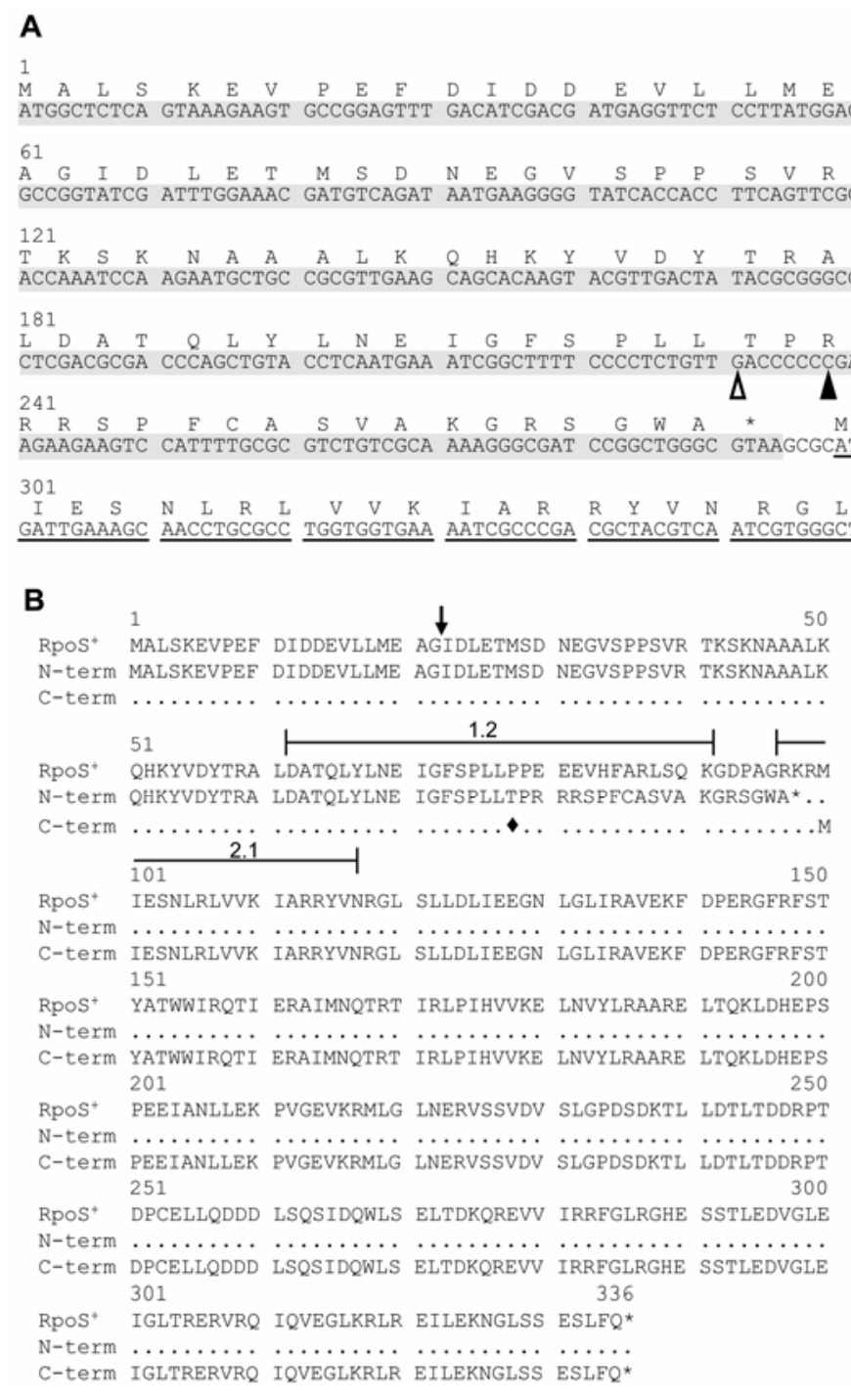

Fig. 1. A, Nucleotide sequence and predicted amino acid sequence of the first 360 nucleotides of rpoS $S^{\mathrm{fs}}$ of Pseudomonas fluorescens strain A506. The shaded nucleotides encode the predicted N-terminal portion and the underlined nucleotides encode the C-terminal portion of the native RpoS of A506. The cytosine residue at position 238 (indicated with an arrowhead) represents a single nucleotide insertion that causes a frameshift, resulting in a termination codon (indicated with an asterisk) at nucleotides 292-294. A second start codon at nucleotides 299-301 initiates translation of the C-terminal portion of the native RpoS. The guanosine residue at position 231 (indicated with an open arrowhead) was eliminated via site-directed mutagenesis to derive a full length, functional RpoS ${ }^{+}$. B, The predicted amino acid sequence of $\mathrm{RpoS}^{+}$and the N-terminal (N-term) and C-terminal (C-term) portions of the native RpoS of A506. The single nucleotide insertion in $\operatorname{rpoS}$ (shown in A) results in a frameshift mutation, with a termination codon at site 97 and a second start codon at site 100. Solid lines indicate two regions (1.2 and 2.1) conserved among sigma factors, with region 1.2 involved in promoter binding (2) and region 2.1 involved in binding to core polymerase (5). The full-length $\mathrm{RpoS}^{+}$, derived by eliminating a guanosine residue at site 231 of the nucleotide sequence using site-directed mutagenesis, has a single amino-acid substitution at position 78 (indicated with a diamond). The site of the $n p t I$ insertion in the rpoS::nptI mutant of A506 is designated with an arrow. 
Culture and harvest of cells used for stress response tests. Bacterial strains were grown in LB or M9 medium with $1 \%$ glucose (wt/vol) at $27^{\circ} \mathrm{C}$ with shaking (200 rpm). Exponentialphase cells were harvested from cultures after $6 \mathrm{~h}$ of incubation. Stationary-phase cells were collected from cultures $4 \mathrm{~h}$ after the optical density ( $\lambda 600 \mathrm{~nm}$ ) of cultures stopped increasing (i.e., entered stationary phase). Bacterial cells were collected by centrifugation $(5,000 \times g, 3 \mathrm{~min})$, washed twice in $10 \mathrm{mM}$ phosphate buffer ( $\mathrm{pH} 7.0$ ), and suspended to a final density of $\approx 1 \times 10^{8} \mathrm{CFU}$ $\mathrm{ml}^{-1}$ in buffer, unless stated otherwise. Three replicate cultures of each strain were evaluated for tolerance to ultraviolet irradiation, freezing, desiccation, and starvation $(52,55)$. Each experiment was repeated at least twice.

Epiphytic fitness of A506 on pear and apple in the field. Pear and apple trees were in experimental orchards at the Oregon State University, Botany and Plant Pathology Field Laboratory near Corvallis, OR, unless stated otherwise. Epiphytic fitness of A506, A506 rpoS::nptI, or A506 rpoS ${ }^{+}$was evaluated on flowers of pear (Pyrus communis L. cvs. Bartlett or Bosc) and apple (Malus $\times$ domestica Borkh., cv. Rome Beauty) (Table 2). Additional experiments evaluating the survival of A506 and derivative strains were conducted on Bartlett pear trees maintained in a screenhouse with $2-\mathrm{mm}^{2}$ mesh steel walls and a fiberglass roof that provides protection from UV and rainfall, and on Bartlett pear in an experimental orchard at the Southern Oregon Research and Extension Center near Medford, OR. Epiphytic behavior of A506 and derivative strains also was monitored on leaves of Bartlett or Bosc pear and Red Delicious apple (Table 2).

Treatments. Treatments were assigned to four individual replicate trees in field plots in a randomized complete block design. A506 and derivatives were cultured for 3 days at $25^{\circ} \mathrm{C}$ on NAgly. Bacteria were scraped from the agar surface and suspended in sterile $10 \mathrm{mM}$ phosphate buffer at a cell concentration of $\approx 1 \times$ $10^{10} \mathrm{CFU} \mathrm{ml}{ }^{-1}$ with the aid of a spectrophotometer (Bausch \& Lomb Spec 20, Rochester, NY), and the concentrated stock solution was transported to the field in an ice chest. In the orchards, bacterial suspensions were diluted with water (local groundwater sources) to $\approx 1 \times 10^{8} \mathrm{CFU} \mathrm{ml}{ }^{-1}$ prior to spraying. The bacterial cell concentration of the applied suspension was confirmed after treatment by dilution plating. Trees with blossom clusters in 50 to $70 \%$ bloom were sprayed with suspensions of A506 or derivatives until near run-off using $(\approx 2$ to 4 liters per tree) 12-liter backpack sprayers fitted with adjustable brass nozzles attached to a hand-held spray wand (Table 2). Similar methods were used to prepare and apply the bacterial strains to leaves of fruit trees, except that only leaves on marked branches of individual trees were sprayed instead of the entire tree (Table 2).

Recovery of bacteria from plant tissues. Ten flowers were harvested from each tree the day after treatments were applied, and then periodically throughout the bloom period, which varied from 7 to 20 days among the seven field trials of this study. Each trial was sampled on four to six different days. Flowers were transported to the laboratory in the individual wells of 12-well sterile plastic plates (Corning Inc., Corning, NY). In the laboratory, the pistil and nectary of each pear flower or the pistil of each apple flower were excised and placed into test tubes containing 1 $\mathrm{ml}$ of sterile $10 \mathrm{mM}$ potassium phosphate buffer, $\mathrm{pH} 7.1$, and the tube was placed in a bath-style sonicator for $3 \mathrm{~min}$. After sonication and mixing by vortexing, $10 \mu \mathrm{l}$ of the sample buffer and two 100-fold dilutions were spread onto PAF amended with cycloheximide plus rifampicin at $50 \mu \mathrm{g} / \mathrm{ml}$ for selective recovery of A506 or A506 rpoS ${ }^{+}$, or on PAF amended with cycloheximide and kanamycin for selective recovery of A506 rpoS::nptI. Bacterial colonies were enumerated after incubation for 3 days at room temperature. The detection limit was $1 \times 10^{2} \mathrm{CFU} /$ flower.

The persistence of A506 and derivatives was examined on fruit. In preliminary experiments, A506 was not detected on the waxy epidermis of fruit but the bacterium could be recovered from the withered floral tissues in the calyx-end of maturing fruit (data not shown). Thus, only calyx-end tissues of fruit were sampled in this experiment. In mid-July (4 months after application of A506, A506 rpoS::nptI, or A506 rpos ${ }^{+}$on flowers), five to six fruit were harvested from the individual trees sprayed during bloom. Individual fruit were placed in resealable bags and transported to the laboratory. The calyx-end of each fruit was excised with a flamed 18 -mm-diameter cork borer and the tissue was placed into $10 \mathrm{ml}$ of sterile $10 \mathrm{mM}$ potassium phosphate buffer and sonicated for $3 \mathrm{~min}$. After sonication and vortexing, bacteria on fruit tissues were enumerated by spreading $100-\mu \mathrm{l}$ samples of the buffer containing the tissue sample and an appropriate dilution series onto PAF amended with the same antibiotics used for floral tissues.

Likewise, phyllosphere populations of A506, A506 rpoS::nptI, or A506 rpoS ${ }^{+}$were estimated on leaves on marked branches that were sprayed with the bacteria. Leaves were sampled the day after treatments were applied, and then five or six more times during the next 6 to 8 days. On each sampling date, 10 leaves were removed from marked branches of individual trees and placed individually in resealable bags. Each leaf was placed in 10 $\mathrm{ml}$ of sterile $10 \mathrm{mM}$ potassium phosphate buffer in a test tube, sonicated, and processed for recovery and enumeration of bacterial populations as described for fruit samples.

TABLE 2. Year, cultivar, tissue sampled, sampling dates, and environmental conditions

\begin{tabular}{|c|c|c|c|c|c|}
\hline \multirow[b]{2}{*}{ Year, cultivar } & \multirow[b]{2}{*}{ Tissue $^{\mathrm{x}}$} & \multirow[b]{2}{*}{ Trial dates ${ }^{\mathrm{y}}$} & \multicolumn{3}{|c|}{ Environmental conditions ${ }^{\mathrm{z}}$} \\
\hline & & & Temp $\left({ }^{\circ} \mathrm{C}\right)$ & No. of days & Rainfall (mm) \\
\hline \multicolumn{6}{|l|}{1997} \\
\hline Bartlett & Flowers & 8 to 23 April (4) & 10.23 & 11 & 71.63 \\
\hline Bosc & Flowers & 13 to 24 April (4) & 11.11 & 9 & 68.07 \\
\hline Rome Beauty & Flowers & 5 to 12 May (5) & 16.02 & 1 & 2.29 \\
\hline Bartlett & Leaves & 8 to 14 August (5) & 21.77 & 0 & 0 \\
\hline Red Delicious & Leaves & 13 to 21 August (4) & 19.75 & 1 & 0.51 \\
\hline \multicolumn{6}{|l|}{1998} \\
\hline Bartlett, screenhouse & Flowers & 3 to 23 April (6) & 8.71 & NA & NA \\
\hline Bartlett & Flowers & 4 to 24 April (6) & 8.91 & 12 & 41.40 \\
\hline Bartlett, Medford & Flowers & 7 to 21 April (5) & 8.82 & 7 & 17.02 \\
\hline Bosc & Flowers & 8 to 22 April (6) & 9.01 & 6 & 21.34 \\
\hline Bosc & Leaves & 11 to 19 July (5) & 19.24 & 0 & 0 \\
\hline Red Delicious & Leaves & 21 to 28 July (5) & 22.96 & 0 & 0 \\
\hline
\end{tabular}

$\mathrm{x}$ Tissue treated with Pseudomonas fluorescens strain A506 and derivatives.

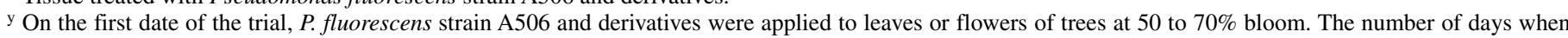
the trial was sampled is shown in parentheses, with the final sample harvested on the last trial date.

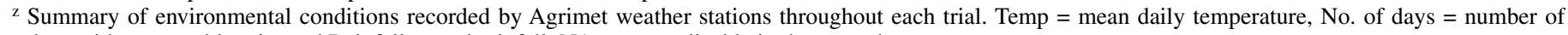
days with measurable rain, and Rainfall = total rainfall; NA = not applicable in the screenhouse. 
Weather data. Weather data spanning the duration of each field experiment were obtained from AgriMet weather stations (Northwest Cooperative Agricultural Weather Network, Bonneville Power Administration, and the U.S. Bureau of Reclamation, Boise, ID) located within the experimental field laboratories near Corvallis and Medford (Table 2).

Data analysis. The mean population sizes of bacterial strains and standard errors were calculated by averaging the logarithm (base 10) of population values obtained from each sample. For samples with a nondetectable bacterial population size, a value of the detection limit minus 1 CFU (99 CFU for plant samples) was assigned to the sample. For analysis of data from laboratory experiments assessing stress tolerance, survival ratios were calculated by dividing the observed population size at a sampling time by the initial population size. Survival ratios were $\log _{10}$-transformed prior to statistical analyses. All population data were subjected to mean separation by Fisher's protected least significant difference test at $P=0.05$ using the analysis of variance (ANOVA) procedure of Statistical Analysis Systems (SAS Institute, Cary, NC).

To compare differences in growth of bacterial strains on flowers or leaves, the relative area under the population curve (RAUPC) was calculated for each tree (replication) in each trial. The area under the population curve (AUPC) was calculated for each replication with the following formula (54):

$$
\mathrm{AUPC}=\sum_{i=1}^{n}\left[\left(y_{i}+y_{i}-1\right) / 2\right] \cdot\left(t_{i}-t_{i-1}\right)
$$

where $y$ is the mean population size of a bacterial strain enumerated from a replication on the $i$ th sample date and $t$ is the corresponding sample time. Because the sample period duration varied among trials, the AUPC was converted to the RAUPC by dividing the AUPC by the elapsed number of days during the sampling period (54). Mean RAUPC values obtained for each bacterial strain were separated with Fisher's protected least significant difference test at $P=0.05$ using the ANOVA procedure of SAS.

\section{RESULTS}

P. fluorescens A506 produces a truncated RpoS protein. The 1,009-bp rpoS gene of A506, identified by hybridization to the rpoS gene from $P$. fluorescens Pf-5, exhibits $92 \%$ sequence identity with an $\operatorname{rpoS}$ gene from $P$. tolaasii (1,011 bp in length) (37) and $85 \%$ sequence identity with an rpoS gene of $P$. fluorescens Pf-5 (1,008 bp in length) (47) at the nucleotide level. Unlike those $r p o S$ genes, however, the region in A506 contains an additional cytosine residue at $238 \mathrm{bp}$ from the predicted start site (Fig. 1). Translation of the region in A506 predicted that the additional nucleotide causes a frameshift mutation, resulting in a stop codon at 292 bp followed by a start codon at 299 bp (Fig. 1). The production by A506 of a truncated form of RpoS was confirmed by western analysis using antibodies specific to the RpoS protein (Fig. 2, lanes 3 to 5). A truncated RpoS protein of $32 \mathrm{kDa}$, the size predicted for the carboxy-terminal open reading frame of the A506 rpoS, was detected in cells harvested from stationary phase cultures of A506, but the protein was not detected in cells of A506 harvested during the exponential phase of growth. The nucleotide sequence immediately $5^{\prime}$ to the start codon at 299 bp did not have obvious similarity to a prokaryotic ribosomal binding site (Fig. 1 ); therefore, the 32-kDa protein was likely generated from a process of translational reinitiation following termination. As a rule, such reinitiation can occur even in the absence of a ribosomal binding site if a suitable start codon is present within 10 nucleotides of a premature stop codon (15). Because only four nucleotides separate it from the termination codon, the AUG codon is likely to serve as the reinitiation site responsible for translation of the observed $32-\mathrm{kDa}$ protein. The absence of a protein corresponding to the amino terminus on western blots may be due to instability of the truncated protein or inability of the polyclonal antibody to recognize this portion of the protein.

Construction of a repaired $\mathrm{rpoS}^{+}$gene. To construct a functional $\mathrm{rpoS}^{+}$gene that could be evaluated for its role in stress response and environmental fitness of A506, the guanosine residue at site 231 in $r p o S^{\mathrm{fs}}$ was deleted using PCR. The nucleotide sequence of the resultant PCR product was obtained to confirm the absence of the guanosine residue in a sequence that is otherwise identical to the corresponding region in the A506 genome. The predicted amino acid sequence of the resultant $r p o S^{+}$gene is a single protein of 335 amino acids (Fig. 1) with $96 \%$ identity to RpoS of $P$. tolaasii and $95 \%$ identity to RpoS of $P$. fluorescens Pf5. We hereafter refer to the repaired rpoS gene of A506 as rpos ${ }^{+}$.

To determine whether $\operatorname{rpoS}^{+}$is functional, we tested its capacity to complement an $r p o S$ mutant of $P$. fluorescens Pf-5 for secondary metabolite production, stress response, and tryptophan sidechain oxidase activity, phenotypes known to be controlled by $r p o S$ in that strain. As demonstrated previously $(47,55)$, the rpoS mutant of Pf-5 was more sensitive than the parental strain to stress imposed by freezing (Fig. 3A). When $r p o S^{+}$was introduced into the $\operatorname{rpoS}$ mutant of Pf-5 on a plasmid, it restored wild-type levels of freezing tolerance to the transconjugants. The level of freezing tolerance conferred by $\operatorname{rpoS}^{+}$was virtually identical to that conferred by the intact rpoS gene from Pf-5 (Fig. 3A). As previously reported (47), an rpoS mutant of Pf-5 produced reduced levels of tryptophan side-chain oxidase (Fig. 3B) and reduced levels of pyrrolnitrin (data not shown), whereas it overproduced pyoluteorin and 2,4-diacetylphloroglucinol (data not shown). The rpoS mutant harboring a plasmid-borne copy of $\mathrm{rpoS}^{+}$produced tryptophan side-chain oxidase (Fig. 3B) and exhibited patterns of secondary metabolite production similar to the parental strain Pf-5 (data not shown). In contrast to $r p o S^{+}$, $r p o S^{\text {fs }}$ did not complement the rpoS mutant of Pf-5 for any of these phenotypes (Fig. 3A and B). Western analysis confirmed that a truncated RpoS, identical in size to the protein observed in A506, was produced in stationary-phase cells of the rpoS mutant of Pf-5 carrying the plasmid-borne copy of $r p o S^{\mathrm{fs}}$ (Fig. 2, lane 10). A full-length RpoS was detected by western analysis in stationary-phase cells of the rpoS mutant of Pf-5 carrying a plasmid that contained rpoS ${ }^{+}$of A506 (Fig. 2, lane 9). These results demonstrate that $\operatorname{rpoS}^{+}$encodes a functional RpoS protein, whereas $r p o S^{\mathrm{fs}}$ does not encode an RpoS protein that is functional in Pf-5.

$\boldsymbol{r p o S}^{+}$and $\operatorname{rpoS}:$ :nptI derivatives of A506. $r p o S^{+}$was introduced into A506 by allelic exchange mutagenesis, resulting in a derivative termed A506 rpoS $S^{+}$The presence of $r p o S^{+}$as the single genomic allele of $r p o S$ in this derivative strain was confirmed by Southern analysis and sequence analysis of PCR products amplified from primers flanking $r p o S^{+}$. A protein of the size expected for the full-length RpoS was detected in stationary-phase cells of A506 rpoS ${ }^{+}$by western analysis (Fig. 2, lane 7).

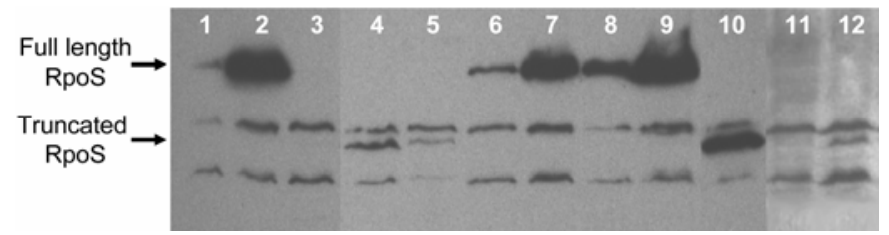

Fig. 2. Detection of RpoS in A506, Pf-5, and derivative strains by western analysis. Lane 1, Pf-5 exponential phase; lane 2, Pf-5 stationary phase; lane 3, A506 exponential phase; lane 4, A506 stationary phase; lane 5, A506 late stationary phase; lane 6, A506 rpos ${ }^{+}$exponential phase; lane 7, A506 rpos stationary phase; lane 8, A506 rpos $S^{+}$late stationary phase; lane 9, Pf-5 rpoS::Tn5 (pJEL6068) stationary phase; lane 10, Pf-5 rpoS::Tn5 (pJEL5942) stationary phase; lane 11, A506 isolate of BlightBan A506 exponential phase; lane 12, A506 isolate of BlightBan A506 stationary phase. RpoS was detected with a polyclonal antibody that is known to cross-react with other proteins in the cell, resulting in several visible bands in western blots (59). 
An rpoS::nptI mutant of A506 also was derived by allelic exchange mutagenesis. RpoS was not detected in the rpoS::nptI mutant of A506 by western analysis (data not shown).

rpoS had little influence on growth rates and tolerance of A506 to various environmental stresses. The growth rates of A506 rpoS $S^{\text {fs }}$ and the derivatives A506 rpoS ${ }^{+}$and A506 rpoS::nptI in the complex media $\mathrm{LB}$ and $\mathrm{KB}$ or in defined M9 medium amended with $1 \%$ glucose or $1 \%$ glycerol were similar (data not shown).

The capacities of $r p o S^{+}, r p o S^{\mathrm{fs}}$, and rpoS::nptI derivatives of A506 to survive exposure to environmental stresses were compared to determine the role of $r p o S$ in stress tolerance of this bacterium. Stationary-phase cells of A506 rpos ${ }^{+}$were significantly more tolerant of starvation stress than were stationaryphase cells of A506 rpoS $S^{\mathrm{fs}}$ and A506 rpoS::nptI (Fig. 4A). No significant difference in tolerance of exponential-phase cells or stationary-phase cells of A506 and its derivatives to stresses imposed by UV irradiation, desiccation, or freezing was observed consistently in repeated experiments (Fig. 4B to E).

Neither A506 nor the derivative strains produced tryptophan side-chain oxidase (Fig. 3B); therefore, the influence of RpoS on tryptophan side-chain oxidase activity could not be assessed directly in this strain.

rpoS had no consistent influence on population establishment of A506 on flowers or long-term persistence on fruit. Populations of A506 and derivative strains were evaluated on flower surfaces of pear or apple in one experiment done in a

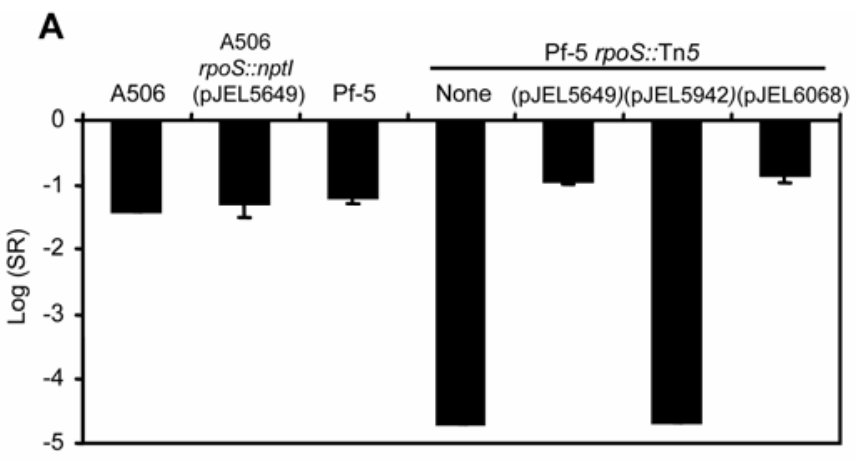

B

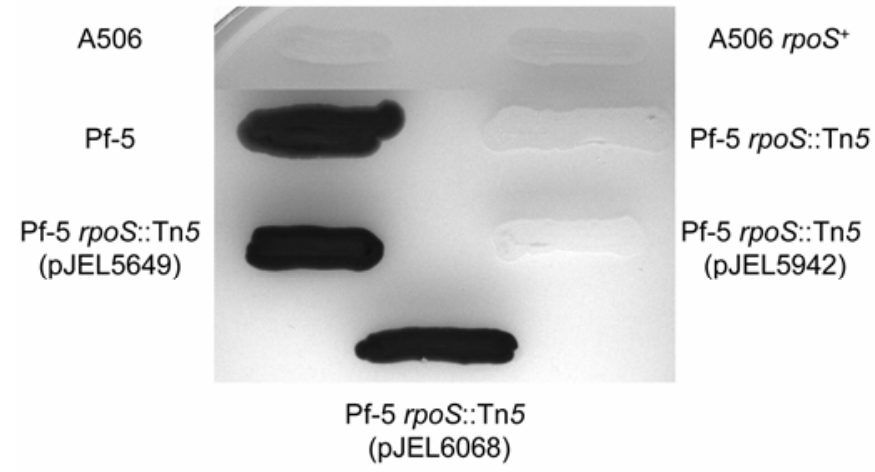

Fig. 3. Complementation of an rpoS mutant of Pseudomonas fluorescens Pf-5. A, Tolerance of exposure to $-20^{\circ} \mathrm{C}$ for $18 \mathrm{~h}$ of stationary-phase cells of A506, Pf-5, Pf-5 rpoS::Tn5, and constructs of Pf-5 rpoS::Tn5 with plasmids containing the functional rpoS of Pf-5 (pJEL5649), rpoS ${ }^{\mathrm{fs}}$ of A506 (pJEL5942), or the repaired $r p o S^{+}$of A506 (pJEL6068). Tolerance is expressed as the logarithm (base 10) of the survival ratio $[\log (\mathrm{SR})]$, which is the culturable population size after freezing divided by the population size in the initial sample. Vertical bars represent one standard error of the mean. B, Tryptophan side-chain oxidase activity exhibited by Pf-5, A506, and derivative strains containing different rpoS constructs. Strains were tested for tryptophan sidechain oxidase activity, which is known to be regulated by rpoS in Pf-5 $(47,55)$, after $48 \mathrm{~h}$ of incubation on an agar medium. Dark colonies were positive for the enzyme and white colonies were negative. The experiment was done twice, yielding similar results. screenhouse and six done in orchard environments. Immediately after the bacteria were sprayed on flowers, their populations varied between $10^{3}$ and $10^{4} \mathrm{CFU} /$ flower (data not shown). Populations typically increased to $5 \times 10^{4}$ to $5 \times 10^{7} \mathrm{CFU} /$ flower during the bloom period (Fig. 5A and B). To represent the population sizes of the strains on flowers over an entire experiment, the RAUPC was calculated for each replicate and a mean RAUPC was calculated for each treatment in a trial. In two of seven trials, the RAUPC for A506 rpoS::nptI was significantly larger than that for the parental strain A506 (Table 3).

Establishment of A506 rpoS ${ }^{+}$was evaluated in four trials. In three of the four trials, the RAUPC of A506 rpos ${ }^{+}$did not differ from the RAUPCs of A506 or A506 rpoS::nptI (Table 3). Analysis of pooled experiments confirmed that there were no significant differences in the population sizes of A506 rpoS::nptI and A506 $r p o S^{+}$on flowers of pear and apple (Table 3).

The survival of bacterial strains on fruit surfaces was evaluated late in the growing season. In 1997, A506 was recovered from $15 \%$ of Rome Beauty apple fruit and $30 \%$ of Bartlett pear fruit sampled $\approx 4$ months after bacteria were applied to the flowers. A506 rpoS::nptI was recovered at a significantly higher incidence, from more than $40 \%$ of Rome Beauty apple fruit and $56 \%$ Bartlett pear fruit sampled. The mean detectable population sizes of A506 and A506 rpoS::nptI on fruit were similar in 1997, with averages of 1.3 to $2.0 \log _{10}$ (CFU/fruit) on Rome Beauty apple and 2.5 to $3.2 \log _{10}$ (CFU/fruit) on Bartlett. In 1998, the incidence of recovery and mean detectable population size of A506, A506 rpoS::nptI, and A506 rpoS ${ }^{+}$on fruit of Bartlett and Bosc pear trees did not differ among strains. A506 and derivatives were recovered from 30 to $45 \%$ of fruit sampled with a mean detectable population size of 1.9 to $2.8 \log _{10}$ (CFU/fruit).

rpoS did not consistently affect survival of A506 on leaves. Populations of A506 and derivative strains were estimated on leaf surfaces of pear or apple in four experiments done in orchard environments. Immediately after spraying bacteria onto leaves, populations of the bacteria were $\approx 10^{5}$ to $10^{6} \mathrm{CFU} /$ leaf. During the following 6 to 9 days, populations typically declined, ranging from $10^{2}$ to $10^{5} \mathrm{CFU} /$ leaf over the course of the experiments (Fig. 5C and D). On leaves of Bartlett pear in 1997, the RAUPC of A506 rpoS::nptI was significantly larger than that of A506 rpos ${ }^{+}$ (Table 4; Fig. 5C). In contrast, on Red Delicious apple in 1997, the opposite was observed, with the RAUPC of A506 rpos ${ }^{+}$significantly larger than that of A506 rpoS::nptI and A506 (Table 4; Fig. 5D). In 1998 trials on pear and apple leaves, there was no difference in the measured RAUPC among strains (Table 4). Analysis of pooled experiments indicated that there were no significant differences in the population sizes of A506, A506 rpoS::nptI, and A506 rpoS ${ }^{+}$on leaves of pear and apple (Table 4).

\section{DISCUSSION}

This study demonstrates that $P$. fluorescens A506, an epiphytic bacterium used commercially for biological control of fire blight, frost injury and russeting of pear, lacks an intact RpoS, which is an important component of stress response systems in other strains of Pseudomonas spp. (16,21,25,32-34,44,47,55,57). The absence of a functional RpoS had no statistically significant effect on the capacity of A506 to colonize leaves, flowers, or fruit of pear and apple in replicated field trials. Isogenic strains derived from A506, differing only in the presence or absence of a functional rpoS, did not differ in their capacities to establish epiphytic populations in a field environment; all strains could be recovered from pear and apple fruit that developed from flowers inoculated 4 months earlier. These results contrast with those from earlier studies demonstrating that $r p o S$ contributes to the survival of other strains of $P$. fluorescens $(55)$ and $P$. putida $(32,44)$ in the rhizosphere. The role of rpoS in A506 appears to be very similar to its role in $P$. fluorescens strain A122 which, like A506, was 

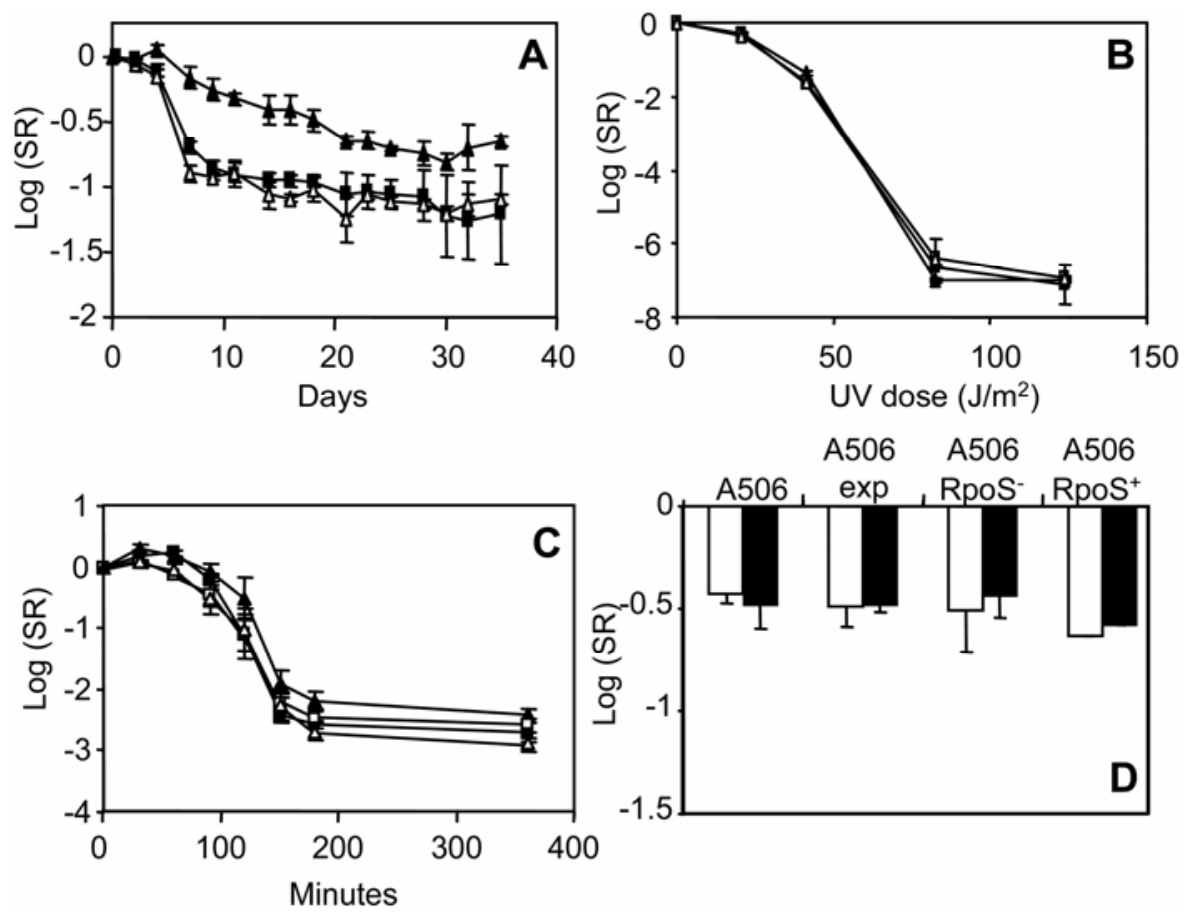

Fig. 4. Effect of rpoS on stress tolerance of Pseudomonas fluorescens A506. Stress tolerance was assessed on exponential phase cells of A506 ( $\square$ or A506 exp) and stationary phase cells of A506 (-), the rpoS::nptI derivative JL4529 (A506 RpoS ${ }^{-}, \Delta$ ), and the construct with the repaired rpoS ${ }^{+}$(A506 RpoS ${ }^{+}, \mathrm{JL}_{4543,} \mathbf{\Delta}$ ) cultured in broth media. Washed cells were exposed to A, starvation (stationary-phase cells only) by suspension in saline; $\mathbf{B}$, UV irradiation; $\mathbf{C}$, desiccation on paper maintained at $75 \%$ relative humidity; and $\mathbf{D}$, freezing at $-20^{\circ} \mathrm{C}$ (white bars) or $-80^{\circ} \mathrm{C}$ (black bars) for $12 \mathrm{~h}$. Tolerance is expressed as the logarithm (base 10 ) of the survival ratio [ $\log (\mathrm{SR})]$, which is culturable population size after a stress exposure period or dose divided by the population size in the initial sample. Vertical bars represent one standard error of the mean, but often they are obscured by the symbol. The results shown are from single representative experiments; each experiment was repeated at least twice and yielded similar responses to those shown in the figure.
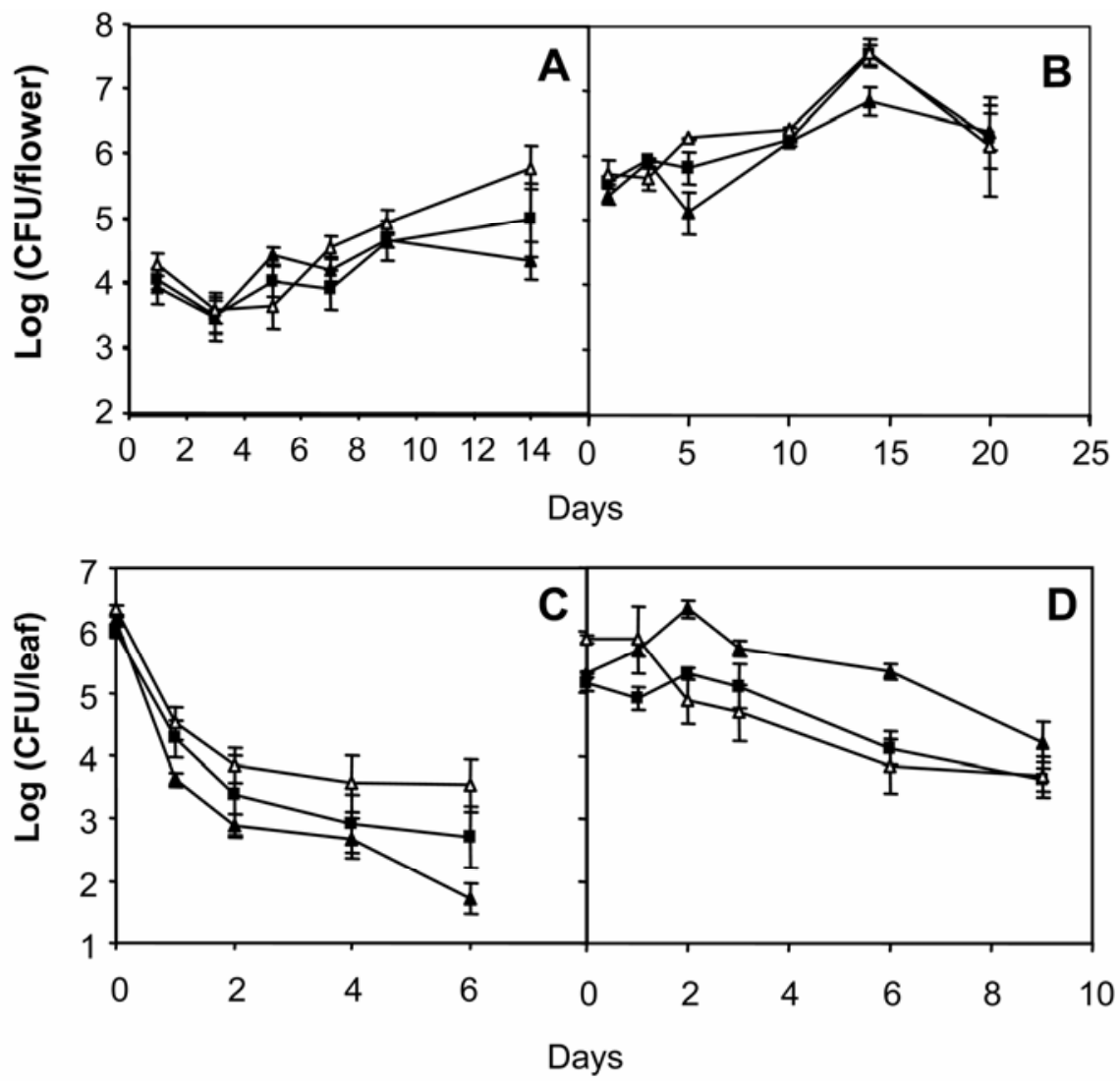

Fig. 5. Effect of rpoS on survival of A506 on A, flowers of Bosc pear; B, flowers of Bartlett pear; C, leaves of Bartlett pear; and D, leaves of Red Delicious apple trees in the field (A, C, and D) or screenhouse $(\mathbf{B})$. Experimental plots consisted of trees assigned to treatments in a randomized block design with four replications per bacterial strain per treatment. Flowers were sprayed with $10^{8} \mathrm{CFU} \mathrm{ml}{ }^{-1}$ and leaves were sprayed with $10^{9} \mathrm{CFU} \mathrm{ml}{ }^{-1}$ suspensions of A506 (匹), the rpoS::nptI derivative JL4529 $(\Delta)$, or the strain with the repaired rpoS ${ }^{+} \mathrm{JL} 4543(\mathbf{\Delta})$. Culturable bacterial populations from the pistillate structures of flowers or leaves were estimated by spreading dilutions of tissue washes on selective media. Vertical bars represent one standard error of the mean. 
isolated from the phyllosphere (52). Together, these studies indicate that RpoS does not have a universal role in environmental fitness of Pseudomonas spp. inhabiting plant surfaces.

We detected no significant influence of RpoS on survival of strain A506 when exposed to UV radiation, desiccation, or freezing. Isogenic strains of A506 differing only in the presence or absence of a functional rpoS exhibited similar capacities to survive exposure to these stresses. A small but significant role for $r p o S$ was observed only in the starvation response of A506. Thus, the role of rpoS in stress response of A506 differs markedly from its role in many other strains of Pseudomonas spp., where rpoS mutants are more sensitive than $r p o S^{+}$parental strains to multiple stresses $(16,21,25,32-34,44,47,55,57)$. It should also be remembered, however, that the minor role of rpoS in stress response is not unique to strain A506; the related strain 122 also does not require RpoS to survive exposure to multiple stresses (52). Furthermore, both A506 and 122 exhibited robust stress-response systems comparable with that of P. fluorescens strain Pf-5 (55; this study). Sigma factors other than RpoS are known to play a role in stress response of $P$. fluorescens. For example, the sigma factor $\mathrm{Alg} \mathrm{U}$ (also called $\mathrm{AlgT}$, RpoE, and $\sigma^{22}$ ), a key determinant of extracellular polysaccharide production, is required for optimal survival of $P$. fluorescens $\mathrm{CHA} 0$ when exposed to desiccation and osmotic stress (49). In addition, $\sigma^{54}$ is required for optimal survival of $P$. fluorescens CHA0 to osmotic stress (42) and of $P$. putida to starvation stress (23). Genomes of Pseudomonas spp. typically have $\approx 30$ sigma factors, with 34 sigma factors present in the genome of $P$. fluorescens Pf-5 (41). The functions of many of these remain unknown, but $\sigma^{\mathrm{S}}, \sigma^{22}$, and $\sigma^{54}$ may not be the only sigma factors that function in stress response in Pseudomonas spp. The results of this study indicate that the relative importance of $\sigma^{\mathrm{S}}$ in stress response varies among strains of Pseudomonas spp.

A506 is a rifampicin-resistant derivative of a strain that was isolated from a pear leaf more than 25 years ago and stored as a stab culture for several years prior to $-80^{\circ} \mathrm{C}$ storage (S. E. Lindow, personal communication). Therefore, it is not possible to know if the rpoS mutation existed in A506 prior to culture or if it arose during storage in the laboratory. The lack of a significant role for RpoS in epiphytic fitness of A506 as well as a relatively minor role in stress resistance suggest that there may be little advantage to A506 in maintaining a functional rpoS either in the field or in culture. Despite the importance of $r p o S$ in stress response, $\operatorname{rpoS}$ mutations are surprisingly common in certain other gram-negative bacteria, such as E. coli $(18,19,38)$ and Salmonella

TABLE 3. Relative area under the population curve (RAUPC) of A506 and derivatives on apple and pear flowers

\begin{tabular}{lccc}
\hline & \multicolumn{3}{c}{ Mean RAUPC } \\
\cline { 2 - 4 } Year, cultivar, location & A506 & A506 rpoS::nptI & A506 rpoS \\
\hline 1997 & & & \\
Bartlett & $4.04 \mathrm{~B}$ & $5.67 \mathrm{~A}$ & $\mathrm{NT}$ \\
Bosc & $5.77 \mathrm{~A}$ & $6.24 \mathrm{~A}$ & $\mathrm{NT}$ \\
Rome Beauty & $4.20 \mathrm{~B}$ & $4.88 \mathrm{~A}$ & $\mathrm{NT}$ \\
1998 & & \\
Bartlett, screenhouse & $6.13 \mathrm{~A}$ & $6.20 \mathrm{~A}$ & $5.82 \mathrm{~A}$ \\
Bartlett & $4.48 \mathrm{~A}$ & $4.64 \mathrm{~A}$ & $4.23 \mathrm{~B}$ \\
Bartlett, Medford & $5.28 \mathrm{~A}$ & $5.38 \mathrm{~A}$ & $5.68 \mathrm{~A}$ \\
Bosc & $4.72 \mathrm{~A}$ & $4.78 \mathrm{~A}$ & $4.82 \mathrm{~A}$ \\
Pooled analyses & $4.85 \mathrm{~B}$ & $5.33 \mathrm{~A}$ & $5.24 \mathrm{AB}$ \\
\hline y All experiments were conducted on pear and apple trees in experimental \\
orchards located at the Oregon State University Botany and Plant Pathology \\
Field Laboratory, except for one trial conducted in a covered screenhouse \\
and one experiment conducted at the Southern Oregon Research and \\
Extension Center near Medford. \\
z Trees arranged in a complete randomized block design with three or four \\
replications per treatment were sprayed at 50 to 70\% bloom with $1 \times 10^{8}$ \\
CFU ml ${ }^{-1}$ of A506, A506 rpoS::nptI (JL4529), or A506 rpoS ${ }^{+}$(JL4543). \\
Means within a row followed by the same letter are not significantly \\
different by Fisher's protected least significance difference at $P=0.05$.
\end{tabular}

typhimurium (45). The heterogeneity of the rpoS gene in E. coli has been attributed to variations in the relative fitness of $r p o S^{+}$ and $r p o S$ mutant strains in different environments (12). Although RpoS is required for optimal stress response of $E$. coli, this advantage is counteracted in certain environments by the reduced growth rate of $r p o S^{+}$cells relative to $r p o S$ mutant cells. Specifically, growth in nutrient limited environments requires genes expressed from sigma factors other than RpoS and these genes are transcribed at higher levels in rpoS mutants, presumably due to the reduced competition for binding to the core RNA polymerase $(38,39) . r p o S$ is the most common site for mutations resulting in the growth advantage in stationary phase (GASP) phenotype of $E$. coli (13), and these mutations include single-base-pair insertions, as found here in rpoS of A506. In contrast to the GASP mutations of $E$. coli, however, the growth rates of $r p o S^{+}$and $r p o S^{\mathrm{fs}}$ and $r p o S$ derivatives of A506 did not differ in a range of minimal and rich media, which suggests that RpoS does not confer a growth disadvantage on A506 in low-nutrient media, as seen in E. coli.

Pseudomonas spp. have several characteristics, including their capacities to colonize plant surfaces and produce antibiotics, that make them well suited as biological control agents (66). Despite these attributes, however, certain strains of Pseudomonas spp. are known to exhibit a genetic instability that can compromise their performance as biological control agents $(11,61,63)$. In certain strains of Pseudomonas spp., mutants deficient in the global regulatory gene pair $g a c S / g a c A$, which is required for the production of many antibiotics that contribute to biological control, accumulate in culture (11) and in the rhizosphere (7). Cultures of Pseudomonas spp. commonly include colonies exhibiting two morphologies, due to a process of phenotypic switching or phase variation (61); and, in at least certain biocontrol strains of Pseudomonas spp., this phenomenon is also attributed to mutations in $g a c S$ or gacA (62). rpoS is known to be regulated positively by $g a c A / g a c S$ in $P$. fluorescens $(16,48,63,67)$, and a proposed model links gacA/gacS, rpoS, and mutS to the phenomenon of phase variation (61). A506 does not harbor a mutation in $g a c A$ or gacS (1), nor does it accumulate gacA/gacS mutations when grown in culture for prolonged periods (V. O. Stockwell, unpublished data). Like the gacA/gacS mutants of P. chlororaphis (7), the rpoS mutants of A506 were not found to be compromised detectably in their environmental fitness on plant surfaces. The finding that A506 has a single nucleotide insertion in rpoS of A506 could indicate that $r p o S$ is a locus, like $\mathrm{gacA} / \mathrm{gacS}$, where mutations can accumulate in the Pseudomonas genome.

In this study, site-directed mutagenesis was employed to derive a strain of A506 that produced a full-length RpoS protein. At the time when the strain was derived, $r p o S$ sequences were available for only two strains of Pseudomonas spp. From nucleotide alignments done at that time, we detected a single nucleotide insertion in the sequence of $r p o S^{\mathrm{fs}}$ from A506 but incorrectly deduced that the additional nucleotide was a guanosine residue at site 231 .

TABLE 4. Relative area under the population curve (RAUPC) of A506 and derivatives on apple and pear leaf tissues

\begin{tabular}{lccc}
\hline & \multicolumn{3}{c}{ Mean RAUPC $^{2}$} \\
\cline { 2 - 4 } Year, cultivar & A506 & A506 rpoS::nptI & A506 rpoS \\
\hline 1997 & & & \\
Bartlett & $3.48 \mathrm{AB}$ & $4.02 \mathrm{~A}$ & $3.02 \mathrm{~B}$ \\
Red Delicious & $4.59 \mathrm{~B}$ & $4.40 \mathrm{~B}$ & $5.49 \mathrm{~A}$ \\
1998 & & & \\
Bosc & $4.17 \mathrm{~A}$ & $4.44 \mathrm{~A}$ & $3.98 \mathrm{~A}$ \\
Red Delicious & $4.62 \mathrm{~A}$ & $4.92 \mathrm{~A}$ & $4.83 \mathrm{~A}$ \\
Pooled analyses & $4.06 \mathrm{~A}$ & $4.28 \mathrm{~A}$ & $4.18 \mathrm{~A}$ \\
\hline
\end{tabular}

${ }^{z}$ Trees arranged in a complete randomized block design with three or four replications per treatment were sprayed with $1 \times 10^{9} \mathrm{CFU} \mathrm{m}^{-1}$ of A506, A506 rpoS::nptI (JL4529), or A506 rpoS $S^{+}$(JL4543). Means within a row followed by the same letter are not significantly different by Fisher's protected least significance difference at $P=0.05$. 
Therefore, the full-length $r p o S^{+}$was derived by removing the $\mathrm{G}$ at site 231. With the benefit of additional rpoS sequences from Pseudomonas spp., it later became apparent that the additional nucleotide in $\operatorname{rpoS}^{\mathrm{fs}}$ is a cytosine residue at site 238. Consequently, the repaired $\mathrm{RpoS}^{+}$has a proline residue at position 78 whereas RpoS proteins from other Pseudomonas strains have a serine or threonine at position 78 . The single amino acid substitution is located in region 1.2 of RpoS, a region involved in promoter binding $(2,71)$. Although certain mutations within region 1.2 of the housekeeping sigma factor $\left(\sigma^{70}\right)$ of $E$. coli result in lost or reduced function (2), the amino acid substitution at position 78 of RpoS of A506 was fully functional in restoring stress response and antibiotic production to P. fluorescens Pf-5 in this study.

The survival of exponential-phase and stationary-phase cells of A506 was very similar when exposed to a variety of environmental stresses in this study. These results differ markedly from the more typical findings that exponentially growing cells of Pseudomonas spp. (47) and other gram-negative bacteria (40) are particularly sensitive to stresses, and assume a more stressresistant state only when the growth rate slows. Epiphytic bacteria encounter rapidly fluctuating environmental conditions on aerial plant surfaces, and their capacity to withstand stresses imposed suddenly is likely to be a key factor contributing to epiphytic fitness. If rapid stress response is an absolute requirement for survival on leaves or flowers, a bacterium may achieve this by possessing redundant regulatory mechanisms that ensure the expression of stress response genes when and where they are needed. Alternatively, a bacterial epiphyte may express stress response genes constitutively, so that it is always prepared for rapid shifts in exposure to UV irradiation, desiccation, or other environmental stresses. The similarity in stress response of stationary-phase and exponential-phase cells of A506 suggests that the bacterium may be in a physiological state that is relatively resistant to environmental stresses throughout its life cycle on plant surfaces, even in those microhabitats or periods of time when it is actively growing. The results of this study argue against the universality of a common model of RpoS in stress response and reveal more diversity in mechanisms of stress response than previously appreciated. A506 may provide an excellent model for future studies evaluating rpoS-independent mechanisms regulating stress response in Pseudomonas spp.

\section{ACKNOWLEDGMENTS}

M. J. Hagen and V. O. Stockwell each conducted central aspects of this research, and their contributions were of equal importance in achieving the results of this work. This research was supported in part by grant $95-$ 37312-1655 from the USDA-CSREES, National Research Initiative Competitive Grants, Biologically-Based Pest Management Program, and a Postdoctoral Research Fellowship to M. J. Hagen from the National Science Foundation, Biosciences Related to the Environment Program. We thank L. M. Anderson and C. Taorimina for excellent technical assistance, B. Shaffer for editorial assistance, K. Tanaka for the gift of the RpoS antiserum, and S. Lindow for his thoughtful review of the manuscript.

\section{LITERATURE CITED}

1. Anderson, L. M., Stockwell, V. O., and Loper, J. E. 2004. An extracellular protease of Pseudomonas fluorescens A506 inactivates antibiotics of Pantoea agglomerans. Phytopathology 94:1228-1234.

2. Baldwin, N. E., and Dombroski, A. J. 2001. Isolation and characterization of mutations in region 1.2 of Escherichia coli $\sigma^{70}$. Mol. Microbiol. 42:427-437.

3. Beattie, G. A., and Lindow, S. E. 1994. Comparison of the behavior of epiphytic fitness mutants of Pseudomonas syringae under controlled and field conditions. Appl. Environ. Microbiol. 60:3799-3808.

4. Beattie, G. A., and Lindow, S. E. 1994. Survival, growth, and localizations of epiphytic fitness mutants of Pseudomonas syringae on leaves. Appl. Environ. Microbiol. 60:3790-3798.

5. Burgess, R. R., and Anthony, L. 2001. How sigma docks to RNA polymerase and what sigma does. Curr. Microbiol. 4:126-131.
6. Casavant, N. C., Thompson, D., Beattie, G. A., Phillips, G. J., and Halverson, L. J. 2003. Use of a site-specific recombination-based biosensor for detecting bioavailable toluene and related compounds on roots. Environ. Microbiol. 5:238.

7. Chancey S. T., Wood, D. W., Pierson, E. A., and Pierson, L. S., 3rd. 2002. Survival of $\mathrm{GacS} / \mathrm{GacA}$ mutants of the biological control bacterium Pseudomonas aureofaciens $30-84$ in the wheat rhizosphere. Appl. Environ. Microbiol. 68:3308-3314.

8. DeLorenzo, V., Herrero, M., Jacubzik, U., and Timmis, K. N. 1990. MiniTn5 transposon derivatives for insertion mutagenesis, promoter probing, and chromosomal insertion of cloned DNA in gram-negative eubacteria. J. Bacteriol. 172:6568-6572.

9. Dianese, A. C., Ji, P. S., and Wilson, M. 2003. Nutritional similarity between leaf-associated nonpathogenic bacteria and the pathogen is not predictive of efficacy in biological control of bacterial spot of tomato. Appl. Environ. Microbiol. 69:3484-3491.

10. Ditta, G., Schmidhauser, T., Yakobson, E., Lu, P., Liang, X. W., Finlay, D. R., Guiney, D., and Helinski, D. R. 1985. Plasmids related to the broad host range vector, pRK290, useful for gene cloning and for monitoring gene expression. Plasmid 13:149-153.

11. Duffy, B. K., and Défago, G. 2000. Controlling instability in gacS-gacA regulatory genes during inoculant production of Pseudomonas fluorescens biocontrol strains. Appl. Environ. Microbiol. 66:3142-3150.

12. Ferenci, T. 2001. Hungry bacteria-definition and properties of a nutritional state. Environ. Microbiol. 3:205-611.

13. Finkel, S. E. 2006. Long-term survival during stationary phase: Evolution and the GASP phenotype. Nat. Rev. Microbiol. 4:113-120.

14. Fravel, D. R. 2005. Commercialization and implementation of biocontrol. Annu. Rev. Phytopathol. 43:337-359.

15. Gold, L., and Stormo, G. 1987. Translational initiation. Pages 1302-1307 in: Escherichia coli and Salmonella typhimurium Cellular and Molecular Biology. F. C. Neidhardt, J. L. Ingraham, K. B. Low, B. Magasanik, M. Schaechter, and H. E. Umbarger, eds. ASM Press, Washington, D.C.

16. Heeb, S., Valverde, C., Gigot-Bonnefoy, C., and Haas, D. 2005. Role of the stress sigma factor RpoS in GacA/RsmA-controlled secondary metabolism and resistance to oxidative stress in Pseudomonas fluorescens CHA0. FEMS Microbiol. Lett. 243:251-258.

17. Hengge-Aronis, R. 2002. Signal transduction and regulatory mechanisms involved in control of the sigma(S) (RpoS) subunit of RNA polymerase. Microbiol. Mol. Biol. Rev. 66:373-395.

18. Ivanova, A., Renshaw, M., Guntaka, R. V., and Eisenstark, A. 1992. DNA base sequence variability in $k a t F$ (putative sigma factor) gene of Escherichia coli. Nucleic Acids Res. 20:5479-5480.

19. Jishage, M., and Ishihama, A. 1997. Variation in RNA polymerase sigma subunit composition within different stocks of Escherichia coli W3110. J. Bacteriol. 179:959-963.

20. Johnson, K. B., Stockwell, V. O., and Sawyer, T. L. 2004. Adaptation of fire blight forecasting to optimize the use of biological controls. Plant Dis. 88:41-48.

21. Jørgensen, F., Bally, M., Chapon-Herve, V., Michel, G., Lazdunski, A., Williams, P., and Stewart, G. S. A. B. 1999. RpoS-dependent stress tolerance in Pseudomonas aeruginosa. Microbiology 145:835-844.

22. Keen, N. T., Tamaki, S., Kobayashi, D., and Trollinger, D. 1988. Improved broad host range plasmids for DNA cloning in gram-negative bacteria. Gene 70:191-197.

23. Kim, Y., Watrud, L. S., and Matin, A. 1995. A carbon starvation survival gene of Pseudomonas putida is regulated by $\sigma^{54}$. J. Bacteriol. 177:18501859.

24. King, E. O., Ward, M. K., and Raney, D. E. 1954. Two simple media for the demonstration of pyocyanin and fluorescein. J. Lab. Clin. Med. 44:301-307.

25. Kojic, M., Degrassi, G., and Venturi, V. 1999. Cloning and characterization of the rpoS gene from plant growth-promoting Pseudomonas putida WCS358: RpoS is not involved in siderophore and homoserine lactone production. Biochem. Biophys. Acta 1489:413-20.

26. Lindow, S. E., Andersen, G. and Beattie, G. A. 1993. Characteristics of insertional mutants of Pseudomonas syringae with reduced epiphytic fitness. Appl. Environ. Microbiol. 59:1593-1601.

27. Lindow, S. E., and Brandl, M. T. 2003. Microbiology of the phyllosphere. Appl. Environ. Microbiol. 69:1875-1883.

28. Lindow, S. E., Mc Gourty, G., and Elkins, R. 1996. Interactions of antibiotics with Pseudomonas fluorescens strain A506 in the control of fire blight and frost injury to pear. Phytopathology 86:841-848.

29. Lindow, S. E., and Suslow, T. V. 2003. Temporal dynamics of the biocontrol agent Pseudomonas fluorescens strain A506 in flowers in inoculated pear trees. Phytopathology 93:727-737.

30. Lowder, M., Unge, A., Maraha, N., Jansson, J. K., Swiggett, J., and Oliver, J. D. 2000. Effect of starvation and the viable-but-nonculturable state on green fluorescent protein (GFP) fluorescence in GFP-tagged Pseudomonas fluorescens A506. Appl. Environ. Microbiol. 66:3160-3165. 
31. Mercier, J., and Lindow, S. E. 2000. Role of leaf surface sugars in colonization of plants by bacterial epiphytes. Appl. Environ. Microbiol. 66:369-374.

32. Miller, C. D., Kim, Y.-C., and Anderson, A. J. 2001. Competitiveness in root colonization by Pseudomonas putida requires the rpoS gene. Can. J. Microbiol. 47:41-48.

33. Miller, C. D., Mortensen, W. S., Braga, G. U. L., and Anderson, A. J. 2001. The rpoS gene in Pseudomonas syringae is important in surviving exposure to the near-UV in sunlight. Curr. Microbiol. 43:374-377.

34. Miura, K., Inouye, S., and Nakazawa, A. 1998. The rpoS gene regulates $\mathrm{OP} 2$, an operon for the lower pathway of xylene catabolism on the TOL plasmid, and the stress response in Pseudomonas putida mt-2. Mol. Gen. Genet. 259:72-78.

35. Monier, J.-M., and Lindow, S. E. 2005. Aggregates of resident bacteria facilitate survival of immigrant bacteria on leaf surfaces. Microb. Ecol. 49:343-352.

36. Monier, J.-M., and Lindow, S. E. 2005. Spatial organization of dualspecies bacterial aggregates on leaf surfaces. Appl. Environ. Microbiol. 71:5484-5493.

37. Murata, H. 1999. Characteristics of stress response in a mushroompathogenic bacterium, Pseudomonas tolaasii, during the interaction with Pleurotus ostreatus and carbon/nitrogen starvation in vitro. Mycoscience 40:81-85.

38. Notley-McRobb, L., King, T., and Ferenci, T. 2002. rpoS mutations and loss of general stress resistance in Escherichia coli populations as a consequence of conflict between competing stress responses. J. Bacteriol. 184:806-811.

39. Nyström, T. 2004. Growth versus maintenance: A trade-off dictated by RNA polymerase availability and sigma factor competition? Mol. Microbiol. 54:855-862.

40. Nyström, T. 2004. Stationary-phase physiology. Annu. Rev. Microbiol. 58:161-181.

41. Paulsen, I. T., Press, C. M., Ravel, J., Kobayashi, D. Y., Myers, G. S. A., Mavrodi, D. V., DeBoy, R. T., Seshadri, R., Ren, Q., Madupu, R., Dodson, R. J., Durkin, A. S., Brinkac, L. M., Daugherty, S. C., Sullivan, S. A., Rosovitz, M. J., Gwinn, M. L., Zhou, L., Schneider, D. J, Cartinhour, S. W., Nelson, W. C., Weidman, J., Watkins, K., Tran, K., Khouri, H., Pierson, E. A., Pierson, L. S., III, Thomashow, L. S., and Loper, J. E. 2005. Complete genome sequence of the plant commensal Pseudomonas fluorescens Pf-5: Insights into the biological control of plant disease. Nat. Biotechnol. 23:873-878.

42. Péchy-Tarr, M., Bottiglieri, M., Mathys, S., Lejbølle, K. B., SchniderKeel, U., Maurhofer, M., and Keel, C. 2005. RpoN $\left(\sigma^{54}\right)$ controls production of antifungal compounds and biocontrol activity in Pseudomonas fluorescens CHA0. Mol. Plant-Microbe Interact. 18:260272.

43. Pfender, W. F., Kraus, J., and Loper, J. E. 1993. A genomic region from Pseudomonas fluorescens Pf-5 required for pyrrolnitrin production and inhibition of Pyrenophore tritici-repentis in wheat straw. Phytopathology 83:1223-1228.

44. Ramos-González, M. I., and Molin, S. 1998. Cloning, sequencing, and phenotypic characterization of the rpoS gene from Pseudomonas putida KT2440. J. Bacteriol. 180:3421-3431.

45. Robbe-Saule, V., Algorta, G., Rouilhac, I., and Norel, F. 2003. Characterization of the RpoS status of clinical isolates of Salmonella enterica. Appl. Environ. Microbiol. 69:4352-4358.

46. Sambrook, J., Mac Callum, P., and Russell, D. 2001. Molecular Cloning: A Laboratory Manual. Cold Spring Harbor Laboratory Press, Cold Spring Harbor, NY.

47. Sarniguet, A., Kraus, J., Henkels, M. D., Muehlchen, A. M., and Loper, J. E. 1995. The sigma factor $\sigma^{\mathrm{S}}$ affects antibiotic production and biological control activity of Pseudomonas fluorescens Pf-5. Proc. Natl. Acad. Sci. USA 92:12255-12259.

48. Schmidt-Eisenlohr, H., Gast, A., and Baron, C. 2003. Inactivation of gacS does not affect the competitiveness of Pseudomonas chlororaphis in the Arabidopsis thaliana rhizosphere. Appl. Environ. Microbiol. 69:18171826.

49. Schnider-Keel, U., Lejbølle, K. B., Baehler, E., Haas, D., and Keel, C. 2001. The sigma factor AlgU (AlgT) controls exopolysaccharide production and tolerance towards desiccation and osmotic stress in the biocontrol agent Pseudomonas fluorescens CHA0. Appl. Environ. Microbiol. 67:5683-5693.
50. Simon, R., Priefer, U., and Puhler, A. 1983. A broad host range mobilization system for in vivo genetic engineering: Transposon mutagenesis in Gram negative bacteria. Biotechnology 1:784-791.

51. Stiner, L., and Halverson, L. J. 2002. Development and characterization of a green fluorescent protein-based bacterial biosensor for bioavailable toluene and related compounds. Appl. Environ. Microbiol. 68:1962-1971.

52. Stockwell, V. O., Hockett, K., and Loper, J. E. 2009. Role of RpoS in stress tolerance and environmental fitness of the phyllosphere bacterium Pseudomonas fluorescens strain 122. Phytopathology 99:689-695.

53. Stockwell, V. O., Johnson, K. B., and Loper, J. E. 1996. Compatibility of bacterial antagonists of Erwinia amylovora with antibiotics used to control fire blight. Phytopathology 86:834-840.

54. Stockwell, V. O., Johnson, K. B., and Loper, J. E. 2002. Antibiosis contributes to biological control of fire blight by Pantoea agglomerans strain Eh252 in the field. Phytopathology 92:1202-1209.

55. Stockwell, V. O., and Loper, J. E. 2005. The sigma factor RpoS is required for stress tolerance and environmental fitness of Pseudomonas fluorescens Pf-5. Microbiology 151:3001-3009.

56. Stockwell, V. O., and Stack, J. P. 2007. Using Pseudomonas spp. for integrated biological control. Phytopathology 97:244-249.

57. Suh, S.-J., Silo-Suh, L., Woods, D. E., Hassett, D. J., West, S. E. H., and Ohman, D. E. 1999. Effect of rpoS mutation on the stress response and expression of virulence factors in Pseudomonas aeruginosa. J. Bacteriol. 181:3890-3897.

58. Takai, K., and Hayaishi, O. 1987. Purification and properties of tryptophan side chain oxidase types I and II from Pseudomonas. Methods Enzymol. 142:195-216.

59. Tanaka, K., and Takahashi, H. 1994. Cloning, analysis, and expression of an rpoS homologue gene from Pseudomonas aeruginosa PA01. Gene 150:81-85.

60. Temple, T., Stockwell, V. O., Loper, J. E., and Johnson, K. B. 2004. Bioavailability of iron to Pseudomonas fluorescens strain A506 on flowers of pear and apple. Phytopathology 94:1286-1294.

61. van den Broek, D., Bloemberg, G. V., and Lugtenberg, B. 2005. The role of phenotypic variation in rhizosphere Pseudomonas bacteria. Environ. Microbiol. 7:1686-1697.

62. van den Broek, D., Chin-A-Woeng, T. F. C., Bloemberg, G. V., and Lugtenberg, B. J. J. 2005. Molecular nature of spontaneous modifications in gacS which cause colony phase variation in Pseudomonas sp. strain PCL1171. J. Bacteriol. 187:593-600.

63. van den Broek, D., Chin-A-Woeng, T. F. C., Bloemberg, G. V., and Lugtenberg, B. J. J. 2005. Role of RpoS and MutS in phase variation of Pseudomonas sp. PCL1171. Microbiology 151:1403-1408.

64. Vieira, J., and Messing, J. 1982. The pUC plasmids, an M13mp7-derived system for insertion mutagenesis and sequencing with synthetic universal primers. Gene 19:259-269.

65. Voisard, C., Bull, C. T., Keel, C., Laville, J., Maurhofer, M., Schnider, U., Defago, G., and Haas, D. 1994. Biocontrol of root diseases by Pseudomonas fluorescens $\mathrm{CHA} 0$ : Current concepts and experimental approaches. Pages 67-89 in: Molecular Biology of Rhizosphere Microorganisms. F. O'Gara, D. Dowling, and B. Boesten, eds.. VCH Publishers, Weinheim, Germany.

66. Weller, D. M. 2007. Pseudomonas biocontrol agents of soilborne pathogens: Looking back over 30 years. Phytopathology 97:250-256.

67. Whistler, C. A., Corbell, N. A., Sarniguet, A., Ream, W., and Loper, J. E. 1998. The two-component regulators GacS and GacA influence accumulation of the stationary-phase sigma factor $\sigma^{\mathrm{S}}$ and the stress response in Pseudomonas fluorescens Pf-5. J. Bacteriol. 180:6635-6641.

68. Wilson, M., and Lindow, S. E. 1993. Effect of phenotypic plasticity on epiphytic survival and colonization by Pseudomonas syringae. Appl. Environ. Microbiol. 59:410-416.

69. Wilson, M., and Lindow, S. E. 1993. Interactions between the biological control agent Pseudomonas fluorescens A506 and Erwinia amylovora in pear blossoms. Phytopathology 83:117-123.

70. Wright, C. A., and Beattie, G. A. 2004. Pseudomonas syringae pv. tomato cells encounter inhibitory levels of water stress during the hypersensitive response of Arabidopsis thaliana. Proc. Natl. Acad. Sci. USA 101:32693274.

71. Zenkin, N., Kulbachinskiy, A., Yuzenkova, Y., Mustaev, A., Bass, I., Severinov, K., and Brodolin, K. 2007. Region 1.2 of the RNA polymerase sigma subunit controls recognition of the -10 promoter element. EMBO J. 26:955-964. 